\title{
PASIËNTONDERRIGSTANDAARDE VIR VERPLEEGPRAKTYK IN
}

ALGEMENE HOSPITALE

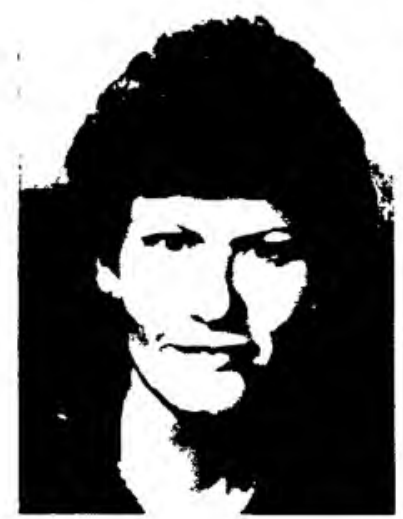

L. Uys

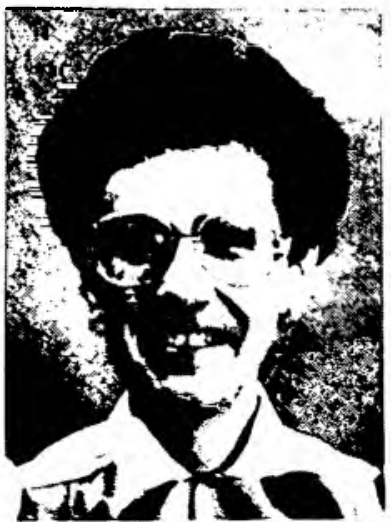

M. Vermaak

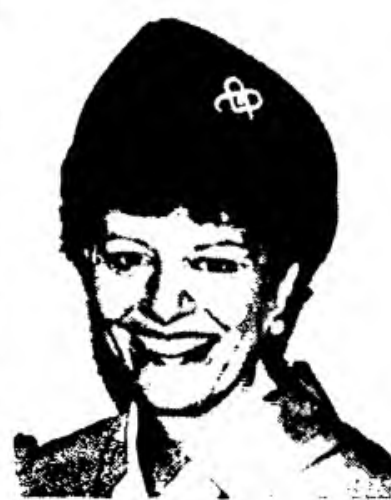

M. Muller

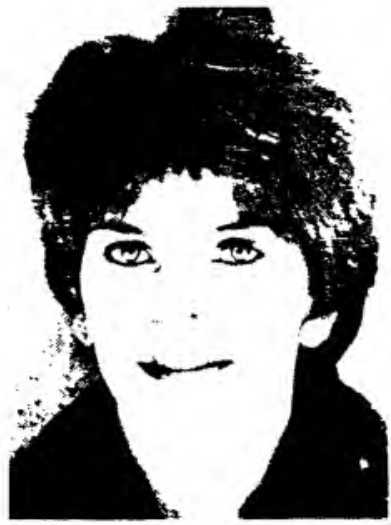

L. Coetzee

\section{LR Uys, MJ Viljoen, MV Vermaak, M Muller, L Coetzee}

\section{INLEIDING}

Hospitalisasie beteken die oorgang van ' $n$ bekende na' $n$ onbekende omgewing en ontketen ' $n$ behoefte aan leer en/of gedragsverandering ten opsigte van sy gesondheidstoestand by die pasiënt. Dit is 'n integrale deel van die verpleegkundige se onafhanklike funksie om ook in hierdie behoefte van die pasiënt te voorsien.

Navorsers dui op ' $n$ aantal positiewe gevolge van pasiëntonderrig (Devine 1986 . p. 99-100 Wilson-Barnett 1983, p. 37) en dit is duidelik dat pasiëntonderrig uiteindelik sal lei tot meer effektiewe pasiëntsorg.

Ten spyte van baie duidelike voordele word hierdie funksie van die geregistreerde verpleegkundige tot 'n groot mate oorgeneem deur paramediese personeel (Brownlee, 1983 p. 102). Ander navorsers bevind dat die aard en kwaliteit van pasiëntonderrig wat wel gedoen word nie na wense is nie (Pera, 1986 Muller, 1986 p. 148-150).

Hierdie ontkenning van die pasiëntonderrigfunksie deur die verpleegkundige word onder andere versterk deur 'n gebrek aan pasiëntonderrigstandaarde. Geformuleerde standaarde wat as maatstaf van kwalitiet dien sal die verpleegkundige weer eens bewus maak van haar funksie in hierdie verband.

\section{DIE DOEL VAN DIE STUDIE}

Die doel van hierdie studie was tweeledig:

1. Om pasiëntonderrigstandaarde vir die gehospitaliseerde pasiënt in die mediese en chirurgiese afdelings te formuleer; en

2. Om pasiëntonderrig evaluasie-instrument te ontwerp.

\section{LITERATUUROORSIG}

\section{Pasiëntonderrigstandaarde}

Die onderrigprogram moet op geldige onderrigstandaarde gebaseer word.

' $n$ Standaard is ' $n$ beskrywende verklaring

\begin{abstract}
Uittreksel
'n Gebrek aan pasiëntonderrigstandaarde is geidentifiseer en die navorsers poog in hierdie studie om standaarde vir pasiëntondderig daar te stel. 'n Instrument vir die meting van pasiëntkennis word ook ontwerp.

\section{Abstract}

A lack of patient education standards was identified and the researchers attempted in this study to develop standards for patient education. An instrument for the evaluation of patient knowledge was also developed.
\end{abstract}

van die verwagte vlak van werkverrigting waarteen die kwaliteit daarvan beoordeel kan word (Gillies, 1982 p. 97)

Kriteria is daardie veranderlikes wat uit standaarde geselekteer word as die maatstaf waarteen kwaliteit gemeet word, dit wil sê "mini-standaarde" (Wright, 1984 p.459)

Daar is hoofsaaklik drie geklassifiseerde standaardverandelikes, soos deur Donabedian (1969) uitgelig. Hierdie model dien as 'n basiese verwysingsraamwerk en klassifiseer standaarde soos volg:

- Struktuurstandaarde;

- Proses-standaarde;

- Produkstandaarde ("Outcome").

Hierdie standaarde is interafhanklike, wisselwerkende elemente wat tot die verbetering van kwaliteit verpleging bydra (Gillies, 1982 p.392).

\section{* Struktuurstandaarde}

'n Struktuurstandaard is die samestelling van die verpleging en die organisasie om gesondheiddienslewering moontlik te maak. Dit behels die volgende:

- die voorbereidingsfase van 'n aktiwiteit;

- die inhoud-insette vanuit die organisasie ten opsigte van die filosofie, beleid en doelstellings van die organisasie;

- die fasiliteite, toerusting en mannekragvermoëns; (Jernigan \& Young, 1983 p. 10).

Volgens Gillies (1982, p. 393) sluit 'n struktuurstandaard die volgende elemente in:

- die fisiese opset;

- die instrumentele aspekte:

- die omgewingsomstandighede waarin die verpleegtussentrede uitgevoer moet word byvoorbeeld die filosofie, doelstellings, gebou, en organisatoriese lisensiëringsvereistes.

Dit behels dus daardie administratiewe- en finansiële prosedures wat diensvoorsiening moontlik maak, personeelvereistes daarstel, die beskikbaarheid en aard van toerusting bepaal en omgewingsverandelikes identifiseer.

\section{* Proses-standaard}

Donabedian (1969) beskryf hierdie soos volg: "The frame of reference here is the care given by health workers. This approach looks at the performance of the carer in relation to the patient's needs" (Wright, 1984 p.458)

Volgens Jernigan \& Young (1983, p.10)

behels ' $n$ proses-standaard die volgende:

- die wyse waarop die aktiwiteit of tussentrede uitgevoer word;

- die aktiwiteite betrokke by die verpleegpraktykbeoefening.

- die verpleegaksies, dit wil sê wat gedoen moet word om kwaliteit verpleging te verskaf.

Gillies (1982, p. 393) beklemtoon dat 'n proses-standaard die stappe van die verpleegproses, naamlik beraming, beplanning, implementering, en evaluering, insluit. Dit sluit dus al die elemente van wetenskaplike verpleging in, byvoorbeeld die neem van geskiedenis by die kliënt, die formulering van doelstellings, die maak van 'n verpleegdiagnose, ensovoorts.

Die proses-standaard is dus die meer komplekse standaard en vereis waarde 
beoordelings deur die kliniese deskundige. "Though this is probably the most time consuming and complex approach to carry out, it may be the most successful in answering the question" is good nursing care being carried out?" (Wright, 1843, p. 458)

\section{* Produkstandaarde ("Outcome")}

Volgens Jernigan \& Young (1983, p. 10) behels hierdie standaarde die volgende:

- dit bepaal die pasiënt/kliënt se gesondheidstatus - of verandering;

- meet dus die pasiënt se verandering ten opsigte van sy gesondheidstatus;

- dit definieër dus die verwagte veranderinge nadat die pasiënt verpleging ontvang het.

"Outcome standards define the expected change in the health status of the client after he has received nursing care. Outcome standards also describe the expected change in the client's satisfaction with the nursing care he has received" (Mason, 1978; p. 3).

Bogenoemde drie standaarde moet dus as 'n eenheid geformuleer word en dien as gedragskriteria waarteen werkverrigting gemeet en beoordeel kan word. Die andaarde moet relevant, realisties en geldig wees. Standaarde moet verkieslik gepubliseer word en vereis derhalwe gereelde hersiening (Gillies, 1982, p. 107)

\section{* Pasiëntonderrig}

Die behoefte aan leer/gedragsverandering is volgens Redman $(181$, p. 11$)$ by die meeste pasiënte intens. Kotze (1979 p. 23) is van mening dat die sieke in sy soeke na hulp en kundigheid 'n hoë verwagting stel. Hy verwag nie net onafhanklikheid ten opsigte van sy gesondheid nie maar ook om dit in "medemenslike bemoeienis" te kry (Kotze. 1979 p. 123).

'n Beplande wetenskaplik saamgestelde onderrigprogram is noodsaaklik vir die gehospitaliseerde pasiënt.

'n Aantal aspekte is by die samestelling van so 'n onderrigprogram van belang:

- die pasiënt se eiesoortige behoeftes asook sy gereedheid vir leer;

doelstellings moet fokus op die behoeftes van die pasiënt;

- die inhoudelike word volgens elke doelstelling gestruktureer en toepaslike media word geselekteer;

- die beplande onderrigprogram moet op wetenskaplike wyse uitgevoer word:

- die bereiking van leerdoelstellings moet formeel beoordeel word.

Die doel van pasiëntonderrig is uiteindelik dat die pasiënt ' $n$ ingeligte periode van hospitalisasie sal ervaar en dat hy begrip ten opsigte van sy fisiese omgewing en siektetoestand demonstreer en verbaliseer.

\section{NAVORSINGSONTWERP}

1. Formulering van standaarde: Met betrekking tot die formulering van standaarde is ' $n$ literatuurstudie onderneem waarna konsep-standaarde aan beide portuur- en kennergroepe voorgelê is om die geldigheid te bepaal.

Stap 1.

2. Metodologiese ontwerp:

'n Instrument is na aanleiding van standaarde wat in die eerste fase geldig bevestig is, ontwerp. Die instrument, 'n vraelys, is deur middel van 'n opname gestandaardiseer. Onderhoudvoering en die ouditering van rekords is as dataversamelingtegnieke gebruik.

\section{METODE}

Stap 1 -Formulering van

Pasiëntonderrigstandaarde

'n Grondige literatuurstudie ten opsigte van pasiëntonderrigstandaarde is onderneem. Konsepstandaarde asook kriteria verbonde aan elke standaard is deur ' $n$ kennergroep geformuleer, aan portuurgroepe voorgelê en verfyn. Die portuurgroep het bestaan uit geregistreerde verpleegkundiges in algemene hospitale in die Oranje-Vrystaat en Natal

Sig- en inhoudsgeldigheid, sowel as kriteria, van die standaarde (sien Tabel 1) is met die hulp van portuurgroepe en kliniese kundiges deur middel van die volgende ordinale graderingskaal bepaal:

1. van toepassing;

2. onduidelik, toepaslikheid bevraagteken;

3. van toepassing maar kan moontlik herformuleer word;

4. hoog van toepassing en goed geformuleer. Hierdie geldigheid is wel bevestig deur middel van ' $\mathrm{n}$ inhoudsgeldigheidsindeks van 3,8 ; byna alle evalueerders het gemeen die standaarde is hoogs van toepassing en goed geformuleer. Enkele aanpassings in grootte. Drie strata is geïdentifiseer waarbinn tien hospitale ewekansig geselekteer is. Alle pasiënte wat binne die geselekteerde hospitaal gekwalifiseer het is in die opname ingesluit totdat ' $n$ tien persent kwota vir die hospitaal bereik is.

\section{Steekproef-realisasie}

'n Loodsondersoek het aangedui dat die steekproef as gevolg van die volgende redes nie sou kon realiseer nie:

- beskikbaarheid van personeel het die ondersoek in klein hospitale bemoeilik;

- 'n tekort aan Zulu-sprekende veldwerkers;

- 'n verblyfprobleem vir Swart veldwerkers op die platteland.

Die steekproef is gewysig en het finaal as volg daaruit gesien:

Altesaam 394 pasiënte is in die studie ingesluit.

\section{DIE INSTRUMENT}

Die instrument het bestaan uit kriteria (sien Tabel 3) wat vanuit die standaarde geformuleer is om as evalueringsverandelikes te dien. 'n Kontrole lys van:
- Ja
- Nee
- Onseker
- Nie van toepassing is as evalueringsgradering gebruik.

\section{TABEL 1}

Standaarde vir pasiëntonderrig

Standaarde is in die vorm van produkstandaarde geformuleer

1. Pasiëntonderrig word aangebied volgens die probleemoplossingsproses.

2. Die pasiënt en sy naasbestaandes ervaar 'n ingeligte periode van hospitalisasie, gegrond op effektiewepasientonderrig.

3. Die pasiënt (en sy naasbestaandes) demonstreer/verbaliseer begrip en kennis ten opsigte van sy siekte en selfversorgingsverantwoordelikhede gegrond op effektiewe ontslagbeplanning.

\begin{tabular}{|c|c|c|c|c|c|c|}
\hline \multicolumn{7}{|c|}{$\begin{array}{c}\text { TABEL } 2 \\
\text { Werklike steekproef }\end{array}$} \\
\hline & & ovs & & & NATAL & \\
\hline & Getal & Ratio & Steekpr & Getal & Ratio & Steekpr \\
\hline $\begin{array}{l}\text { Groot Hospitale } \\
\text { ( } 500+\text { beddens) }\end{array}$ & 3 & 1 & 2 & 10 & 1 & 2 \\
\hline $\begin{array}{l}\text { Middelslag } \\
(200-499)\end{array}$ & 6 & 2 & 3 & 17 & 2 & 2 \\
\hline Klein & 23 & 8 & 0 & 16 & 2 & 1 \\
\hline TOTAAL & 32 & 11 & 5 & 43 & 5 & 5 \\
\hline
\end{tabular}

formulering is voorgestel wat in sommige gevalle wel gedoen is.

Nadat standaarde geformuleer en geldig bevestig is, kon voortgegaan word met die ontwerp van die instrument.

\section{POPULASIE EN STEEKPROEF}

Die studiepopulasie is geïdentifiseer as alle pasiënte in mediese en chirurgiese sale in die Vrystaat en Natal wat op die opname dag vir ontslag gereed was.

Die steekproef is geselekteer deur middel van stratifikasie van hospitale volgens

\section{INSAMELING VAN DATA}

Vyf geregistreerde verpleegkundiges is as veldwerkers aangestel. In die meeste gevalle kon hulle die taal van die pasiënt praat. Alle veldwerkers het opleiding ontvang in die gebruik van die instrument.

Inligting is versamel deur middel van onderhoudvoering met pasiënte en ouditering van hul rekords, en is dien ooreenkomstig op die instrument aangedui.

\section{ETIESE ASPEKTE}

Toestemming vir die ondersoek is van alle 
betrokke owerhede verkry. Afsonderlike toestemming is van elke pasiënt verkry nadat die doel en verloop van die ondersoek aan hom/haar verduidelik is. Pasiënte is verseker dat inligting as vertroulik beskou sal word.

\section{RESULTATE}

\section{Betroubaarheid}

Aangesien dit hier gaan oor bevestiging van die betroubaarheid van die instrument is daar vir interne konsekwentheid sowel as interwaarnemerbetroubaarheid getoets.

\section{Interne konsekwentheid van items}

Die Kuder Richardson (K.R 20) is gebruik en 'n algehele Alpha waarde van 0,88 is verkry wat bewys dat die instrument hoogs betroubaar is.

\section{Inter-waarnemer betroubaarheid}

Inter-waarnemer-betroubaarheid is op dertig evaluasies uitgevoer. 'n Algehele interwaarnemer-betroubaarheid is bevestig deur 'n Chi-kwadraat van 0.79 . Die itembetroubaarheid toon leemtes by veral daardie vrae waar 'n "nie van toepassing"-gradering toegeken is. Die konkrete vrae, waar die evalueerder aan die pasiënt gevra het of die verpleegkundige met opname hom ten opsigte van sy kamer, toilet, klokkie, ensovoorts georiënteer het, het 'n korrelasie-koëffisiënt van 1,00 getoon en is dus hoogs betroubaar.

Die pasiënt wat nie vir chirurgie gegaan het nie sou nie positief op enige postoperatiewe verwagtinge en voorbereiding kon antwoord nie. Die vraag wat hoofsaaklik oor hierdie aspek handel toon 'n lae korrelasie koeffisient van 0,5908 tot 0,1761 . Hierdie lae betroubaarheid kan aan die foutiewe gebruik van die instrument toegeskryf word. Die evalueerders het 'n "nie-van toepassing"gradering met 'n "nee" -gradering verwar.

Die instrument is tov enkele items aangepas.

\section{* Geldigheid \\ Inhoudsgeldigheid}

Die toegepaste "State-Trait anxiety Inventory" angsskaal is by die instrument ingesluit en 'n korrelasie tussen die pasiënt se vlak van angs en kennis is gedoen. Pasiënte se angsvlakke was egter laag en geen korrelasie kan bevestig word nie. Die navorsers skryf dit toe aan die tydstip van onderhoudvoering, dit was net voor ontslag en lae angsvlakke kan dan te wagte wees.

\section{Konstrukgeldigheid}

Hierdie geldigheid is gebaseer op die konstruk dat die vlak van onderwys in die onderskeie hospitale verskil.

Die algehele inter-waarnemerbetroubaarheid toonaan dat die huidige instrument wel bruikbaar is. Daar moet in die onderrig van veldwerkers aan die spesifieke betekenis van die onderskeie items aandag gegee word.

TABEL 3

Evalueringsveranderlikes vir Standaarde geidentifiseer

\section{STANDAARD}

Pasiëntonderrig word aangebied volgens die probleemoplossingsproses.

Die algemene beramingsinstrument inkorporeer leerbehoeftes

Gereedheid vir leer word beraam.

Doelstellings word vir onderrig gestel.

Inhoud van onderrig word gestipuleer.

Metodes en tegnieke word aangedui.

Evaluasie van leer geskied volgens doelstellings.

\section{STANDAARD 2}

Die pasiènt en naasbestaandes ervaar ' $n$ ingeligte periode van hospitalisasie, gegrond op effektiewe pasiënt-onderrig.

Die pasiënt is ten opsigte van sy fisiese omgewing ingelig tydens hospitalisasie.

Die pasiënt demonstreer/verbaliseer kennis ten opsigte van die rede vir hospitalisasie

- die aard en inlensiteit van sy siekte;

- die moontlike verloop (prognose) van sy siekte:

- die moontlike gevolge van die siekte; fisies en psigososiaal

- sy deelname aan die versorging.

Die pasiënt wat vir chirurgie sowel as sy naasbestaandes verbaliseer begrip ten opsigte van pre-operatiewe inligting: - die verwagte hospitaalverblyf sonder komplikasies;

- die doel van die chirurgie:

- ligging/moontlike grootte van die insnyding:

- die funksies van die betrokke organe en moontlike veranderinge as gevolg van die chirurgie:

- die moontlike skeduleringstye van chirurgie:

- die aard van pre-operatiewe voorbereidings: skeer, bloedtoetse, $X$-straal ondersoeke, rook verbode, toestemming en uithongering ensovoorts:

- post-operatiewe verwagtinge soos pyn, dreineringsbuise, steke, urinêre kateter, infuus, moontlike ontwrigting van dieet, slaappatroon, ensovoorts:

- die gebruik van gespesialiseerde toerusting post-operatief ensovoorts;

- die aktiwiteite wat vereis word om potensiële post-operatiewe komplikasies te voorkom;

- progressiewe selfversorgingsaksies: bad, dieet mobiliseer, ensovoorts.

Die pasiënt demonstreer/verbaliseer kennis ten opsigte van diagnostiese ondersoeke/behandeling wat uitgevoer word met betrekking tot:

- die doel en aard van die ondersoek/ behandeling:

- die moontlike gevolg/verwagtinge na die ondersoek/behandeling.

- voor-intra- en nasorg wat aanbeveel word

\section{STANDAARD 3}

Die pasiënt (en sy naasbestaandes) demonstreer/verbaliseer begrip en kennis ten opsigte van sy siekte en selfversorgingsverantwoordelikhede. gegrond op effektiewe ontslagbeplanning:

- liggaamlike veranderinge/beperkinge volgens die pasiënte se siekte/gesondheidstoestand;

- normalisering van lewensaktiwiteite: sosialisering, werk, dieet, oefening seksuele aktiwiteite, higiëne (insluitend wondsorg).

Die instrument is by die SAVV in Sotho, Zulu, Engels en Afrikaans beskikbaar, en die riglyne vir die gebruik daarvan is in Engels en Afrikaans beskikbaar.

\section{ERKENNING}

Hierdie studie is deur die Raad vir Geesteswetenskaplike Navorsing en die SuidAfrikaanse Verpleegstersvereniging finansier en menings hierin uitgespreek is nie noodwendig die van die instansies nie.

Die Sentrum vir Toegepaste Sosiale Wetenskappe, Universiteit van Natal, was behulpsaam met die dataverwerking. Alle owerhede wat in die Vrystaat en Natal betrokke was word ook bedank vir hul vriendelike samewerking.

\section{BIBLIOGRAFIE}

Brownlee, E B I (Samesteller) (1983). Die susters in-bevel van hospitaalsale - 'n waardebepaling. Pretoria: UNISA.

Donabedian, A (1969). Medical Care Appraisal quality and utilization. A guide to Medical Administration. New York: American Public
Health Associations.

Devine, E D; Cook, T D (1986). Clinical and costsaving effects of psycho-educational interventions with surgical patient's - research in nursing and health (9:85 105).

Gillies, D A (1982). Nursing Management - a system approach. Philadelphia: WB Saunders.

Jernigan, D K; Young A B (1983). Standards, Joh Descriptions, and Performance Evaluations $f$ Nursing Practice. Norwalk: A C C.

Kotze, W J (1979). Begeleiding in die Verpleegkunde. Pretoria: SAVV

Mason, E J (1978). How to write meaningful nursing standards. New York: Wiley and sons

Muller, M E (1986). Kwaliteitsversekering in 'n kardio-torakale verpleegeenheid. Verhandeling: UNISA (ongepubliseerd).

Pera, S A (1986). Nursing in the private health services in the RSA - a profile of professional practice D.Cur. Proefskrif: UPE (ongepubliseerd).

Redman, B K (1981). Issues and concepts in patient education. New York: AppletonCentury-Crofts.

Wilsong-Barnett, B A; Osborne, J (1983). Studies evaluating patient teaching - implications for practice. International Journal of Nursing Studies Vol. 20 (1). p. 33-44.

Wright, D (1984). An introduction to the evaluation of nursing care - a review of the literature. Journal of Advanced Nursing. Vol. 9 (6) p. 457. 467 